\title{
Charles Evans Hughes
}

Politics and Reform in New York

$$
\text { 1905-1910 }
$$


This page intentionally left blank 


\section{$\underline{\text { ABOUT FALL CREEK BOOKS }}$}

Fall Creek Books is an imprint of Cornell University Press dedicated to making available again classic books that document the history, culture, natural history, and folkways of New York State. Presented in new paperback editions that faithfully reproduce the contents of the original editions, Fall Creek Books titles will appeal to all readers interested in New York and the state's rich past. 


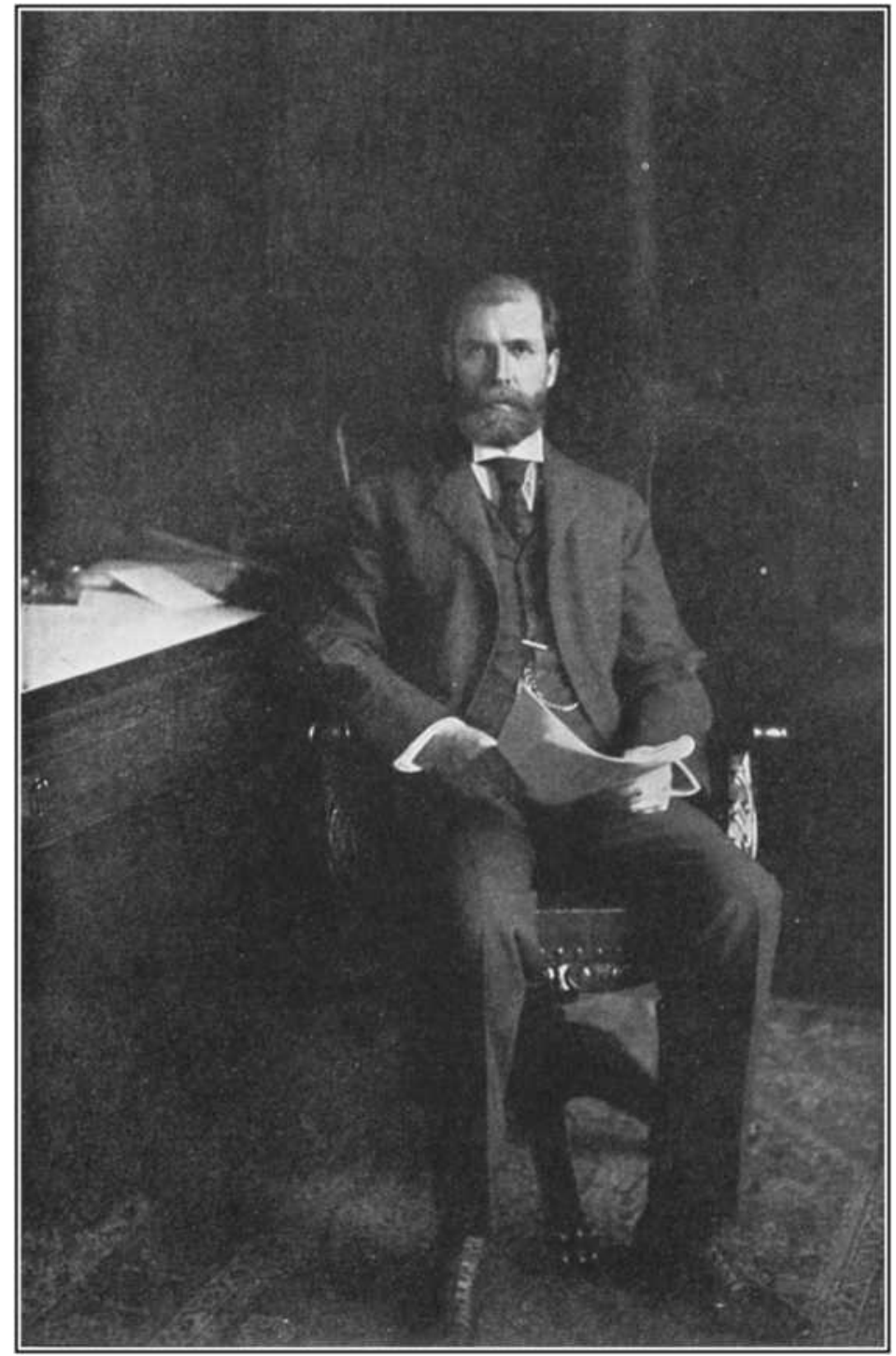

Governor Charles Evans Hughes at his desk in the executive chamber at Albany. (From McClure's, XXX [1907-1908], 525; courtesy of the Cornell University Library.) 


\title{
Charles Evans Hughes
}

\section{Politics and Reform in New York}

\section{5-1910}

\section{BY ROBERT F. WESSER}

\author{
State University of New York at Albany
}

Cornell University Press

ITHACA, NEW YORK 


\title{
Copyright (C) 1967 by Cornell University
}

All rights reserved. Except for brief quotations in a review, this book, or parts thereof, must not be reproduced in any form without permission in writing from the publisher. For information address Cornell University Press, 124 Roberts Place, Ithaca, New York $14^{8} 5^{\circ}$.

First publisbed 1967

First printing, Cornell Paperbacks, 2009

Library of Congress Catalog Card Number: 67-19029

\author{
PRINTED IN THE UNITED STATES OF AMERICA \\ BY VAIL-BALLOU PRESS, INC.
}


To my parents 
This page intentionally left blank 